\title{
Comparison of clinical efficacy between ultra-LABAs and ultra- LAMAs in COPD: a systemic review with meta-analysis of randomized controlled trials
}

\author{
Eun Yeong Cho ${ }^{1 \#}$, Se Yong Kim ${ }^{1 \#}$, Min-Ji Kim², Seonwoo Kim², Dong Ah Park ${ }^{3}$, Kwang Ha Yoo ${ }^{4}$, \\ Yong Bum Park ${ }^{5,6}$, Yong Il Hwang ${ }^{7}$, Chin Kook Rhee ${ }^{8}$, Ji Ye Jung ${ }^{9}$, Hyun Lee ${ }^{10 *}$, Hye Yun Park ${ }^{1 *}$ \\ ${ }^{1}$ Division of Pulmonary and Critical Care Medicine, Department of Medicine, Samsung Medical Center, Sungkyunkwan University of Medicine, \\ Seoul, South Korea; ${ }^{2}$ Statistics and Data Center, Research Institute for Future Medicine, Samsung Medical Center, Seoul, South Korea; ${ }^{3}$ Division of \\ Healthcare Technology Assessment Research, Office of Health Technology Assessment Research, National Evidence-based Healthcare Collaborating \\ Agency, Seoul, South Korea; ${ }^{4}$ Department of Internal Medicine, Konkuk University School of Medicine, Seoul, South Korea; ${ }^{5}$ ivision of \\ Pulmonary, Allergy and Critical Care Medicine, Department of Internal Medicine, Hallym University Kangdong Sacred Heart Hospital, Seoul, \\ South Korea; ${ }^{6}$ Lung Research Institute of Hallym University College of Medicine, Chuncheon, South Korea; ${ }^{7}$ Division of Pulmonary, Allergy and \\ Critical Care Medicine, Department of Internal Medicine, Hallym University Sacred Heart Hospital, Anyang, South Korea; ${ }^{8}$ Division of Pulmonary, \\ Allergy and Critical Care Medicine, Department of Internal Medicine, Seoul St Mary's Hospital, College of Medicine, The Catholic University of \\ Korea, Seoul, South Korea; 'Division of Pulmonology, Department of Internal Medicine, Institute of Chest Disease, Severance Hospital, Yonsei \\ University College of Medicine, Seoul, South Korea; ${ }^{10}$ Division of Pulmonary Medicine and Allergy, Department of Internal Medicine, Hanyang \\ University College of Medicine, Seoul, South Korea \\ Contributions: (I) Conception and design: EY Cho, SY Kim, H Lee, HY Park; (II) Administrative support: KH Yoo, YB Park, YI Hwang, CK Rhee, \\ JY Jung; (III) Provision of study materials or patients: EY Cho, SY Kim, H Lee, HY Park; (IV) Collection and assembly of data: EY Cho, SY Kim, \\ H Lee, HY Park; (V) Data analysis and interpretation: EY Cho, SY Kim, MJ Kim, S Kim, DA Park, H Lee, HY Park; (VI) Manuscript writing: All \\ authors; (VII) Final approval of manuscript: All authors. \\ "These authors contributed equally to this work and should be considered to co-first authors. \\ *These authors contributed equally to this work and should be considered to co-corresponding authors. \\ Correspondence to: Hye Yun Park. Division of Pulmonary and Critical Care Medicine, Department of Medicine, Samsung Medical Center, \\ Sungkyunkwan University School of Medicine, 81 Irwon-ro, Gangnam-gu, Seoul, 06351, South Korea. Email: hyeyunpark@skku.edu.
}

Background: A single long-acting bronchodilator, ultra-long acting muscarinic antagonist (ultra-LAMA) or ultra-long acting $\beta_{2}$-agonist (ultra-LABA) is preferred for the initial treatment of patients with chronic obstructive pulmonary disease (COPD); however, there are few head-to-head comparative studies between the two. Here, a meta-analysis of randomized controlled trials was performed to compare the clinical efficacy between ultra-LABA and ultra-LAMA in patients with moderate-to-severe COPD.

Methods: MEDLINE, EMBASE, and the Cochrane Central Register of Controlled Trials were searched (to March 1, 2017) to identify all published randomized controlled trials.

Results: Of the 12,906 articles found by searching the databases, we obtained data from 10,591 patients with COPD (LABA, n=5,058; LAMA, n=5,533) in seven published studies. Our results showed that COPD exacerbation were significantly lower in patients taking ultra-LAMA than those taking ultra-LABA (odds ratio $=0.857, \mathrm{P}=0.0008$ ). However, no significant differences were observed between ultra-LAMA and ultraLABA patients regarding improvement in trough forced expiratory volume in $1 \mathrm{~s}$, the transitional dyspnea index, or St. George's Respiratory Questionnaire score.

Conclusions: This study suggests that COPD exacerbation occurred less often in patients taking an ultraLAMA than in those taking an ultra-LABA with similar efficacy of lung function and quality of life.

Keywords: Chronic obstructive pulmonary disease (COPD); ultra-long acting $\beta_{2}$-agonist (LABA); ultra-longacting muscarinic antagonist (LAMA); meta-analysis

Submitted Apr 10, 2018. Accepted for publication Sep 26, 2018.

doi: $10.21037 /$ jtd.2018.11.50

View this article at: http://dx.doi.org/10.21037/jtd.2018.11.50 


\section{Introduction}

Chronic obstructive pulmonary disease (COPD) is a common respiratory disease characterized by largely irreversible airflow limitation (1). It is a major global health burden, and its prevalence is expected to increase, with an estimated annual death rate of over 4.5 million worldwide by 2030 (2). COPD patients often have chronic respiratory symptoms, exercise intolerance, and poor health-related quality of life, contributing to significant use of healthcare resources (1). In addition, a considerable proportion of COPD patients experience acute exacerbation and the frequent exacerbations are associated with rapid decline in lung function $(3,4)$, aggravated quality of life $(5,6)$, and increased mortality (7-10).

Long-acting bronchodilators are the cornerstone of the maintenance treatment in moderate to very severe COPD patients (1). Recently, numerous combinations of a long acting $\beta_{2}$-agonist (LABA) and a long-acting muscarinic antagonist (LAMA) have been introduced in a single inhaler device, which showed consistently greater improvement in lung function than long acting bronchodilator monotherapy (11). However, single bronchodilators (LAMA or LABA) are still preferred as an initial treatment in a majority of COPD patients, and the combination of LABA/LAMA is recommended when patients have persistent symptoms despite the use of a single long-acting bronchodilator or experience frequent exacerbations (1). In addition, when patients do not obtain relief of symptoms with the addition of a second bronchodilator, step-down to a single bronchodilator is suggested. Among single long-acting bronchodilators, once-daily long-acting bronchodilators are preferred to twice-daily long-acting bronchodilators due to the advantage of covering a $24 \mathrm{~h}$ therapeutic window, which leads to improvements in drug adherence and treatment response (12-14).

Among long-acting bronchodilators, tiotropium is preferred for exacerbation prevention based on comparison to LABAs in two head-to-head comparisons $(15,16)$. However, one of these two studies compared efficacy between tiotropium and salmeterol, a twice-daily LABA (15), and there is an absence of head-to-head comparative trials with newly introduced once-daily LAMA and LABA. Since there are no sufficient data supporting the use of oncedaily LAMA (ultra-LAMA) over once-daily LABA (ultraLABA) for exacerbation in COPD patients, we conducted a systemic review and meta-analysis for the comparisons of the clinical efficacy and safety of ultra-LABA (indacaterol, olodaterol, or vilanterol) and ultra-LAMA (tiotropium, glycopyrronium or umeclidinium) in stable patients with moderate to severe COPD.

\section{Methods}

\section{Search strategy}

This systematic review is reported in accordance with the Preferred Reporting Items for Systematic Reviews and Meta-Analyses (PRISMA) statement (Figure 1) (17). We identified published studies from MEDLINE, EMBASE, and the Cochrane Central Register of Controlled Trials (up to March 1, 2017) databases using keywords related to COPD, LABAs, LAMAs, and randomized control trials (RCTs). The title and abstract were independently analyzed by two authors (E.Y.C and S.Y.K) for screening. Trials published solely in abstract form were excluded because the methods and results could not be fully analyzed. They independently assessed all studies for inclusion based on the criteria for study design, outcome, and intervention for participants. After they obtained full texts that could be potential candidates, they assessed and confirmed eligibility for the analysis. Disagreements were discussed and resolved by consensus.

\section{Inclusion and exclusion criteria}

The inclusion criteria for this study were as follows: (I) patients with moderate-to-severe COPD by Global Initiative for Chronic Obstructive Lung Disease (GOLD) diagnostic criteria; (II) randomized control trials (RCTs) with comparisons of ultra-LABAs (indacaterol, olodaterol, or vilanterol) and ultra-LAMAs (glycopyrronium, tiotropium, or umeclidinium); (III) at least 12 weeks of follow-up; and (IV) written in English. In this study, ultraLABAs and ultra-LAMAs were defined as once-daily bronchodilators (18).

\section{Data extraction}

Data from the included studies were extracted and assessed for study characteristics and duration, doses of medications, inhaler devices, disease characteristics, age, sex, smoking history, trough forced expiratory volume in 1 second $\left(\mathrm{FEV}_{1}\right)$, St. George's Respiratory Questionnaire (SGRQ) total score, transition dyspnea index (TDI), and COPD worsening and exacerbation. 


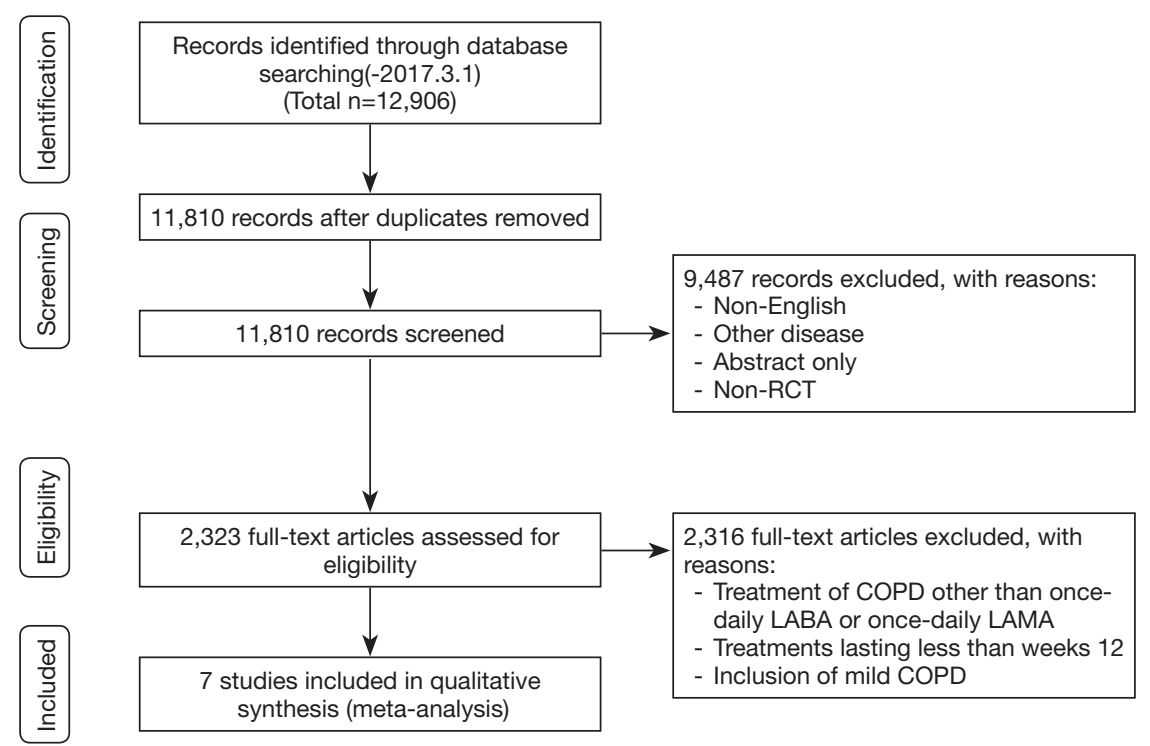

Figure 1 Flowchart for the identification of studies included in the meta-analysis.

\section{End points}

The primary end point of this meta-analysis was the COPD exacerbation of ultra-LABAs versus ultra-LAMAs. COPD exacerbation was extracted from the reports of COPD worsening as the adverse events from six studies and in Decramer et al., the reports of COPD exacerbation with treatments was applied to COPD exacerbation (19). It is because Decramer et al. (19) reported only serious adverse events of exacerbation as adverse events. The secondary end points were change of trough $\mathrm{FEV}_{1}$ from baseline to the first follow-up after week 12 ( $\geq$ week 12), and St. SGRQ total score and TDI at the first follow-up after week 12 ( $\geq$ week 12). Since trough $\mathrm{FEV}_{1}$, SGRQ score, and TDI were measured at different time points according to the study protocol of each study, we used the data obtained at the first follow-up (week 12, week 24, or week 26) after week 12 from each study for the comparisons. The mean value of outcomes was used in the one study including two ultra-LAMAs (glycopyrronium and tiotropium) (20).

\section{Risk of bias assessment}

Two reviewers independently assessed the risk of bias of the included studies for sequence generation, allocation concealment, blinding of participants and researchers, blinding of outcome assessment, incomplete outcome data addressed, and free of selective reporting as recommended in the Cochrane Handbook of Systematic Reviews 5.1. (21).

\section{Statistical analysis}

Statistical analysis was performed using the R 3.3.2 (Vienna, Austria; http://www.R-project.org/) package 'metafor' for meta-analysis of the included studies. Mean differences (MDs) or odds ratios (ORs) for end points were estimated and tested under the fixed effect model or the random effect model. The pooled data were applied to a random effect model if heterogeneity was present in the data of more than 4 studies and to a fixed effect model otherwise. The precision of the estimates was quantified by the $95 \%$ confidence interval (CI). Heterogeneity was measured using the Higgins and Green $\mathrm{I}^{2}$ test, which is calculated as $100 \% \times(\mathrm{Q}-\mathrm{df}) / \mathrm{Q}$, where $\mathrm{Q}$ is the observed chi-square statistic, and the degrees of freedom (df) is the number of studies less one. The value of $\mathrm{I}^{2}$ ranges between $0 \%$ (no heterogeneity) and 100\% (maximal heterogeneity), and heterogeneity was considered to be mild $(<30 \%)$, moderate (30-60\%), and high (>60\%) (21). We also evaluated potential publication bias using Egger's regression test and the funnel-plot (22). P values $<0.05$ (two-tailed test) were considered significant.

\section{Results}

\section{Study characteristics}

Figure 1 shows how the relevant studies were identified. A total of 12,906 articles were found by searching databases. 
Table 1 Characteristics of included studies

\begin{tabular}{|c|c|c|c|c|c|c|c|c|c|c|c|}
\hline Study & $\begin{array}{l}\text { Patient } \\
\text { characteristics }\end{array}$ & $\begin{array}{l}\text { Treatment } \\
\text { period } \\
\text { (weeks) }\end{array}$ & $\begin{array}{l}\text { Number of } \\
\text { subjects }\end{array}$ & $\begin{array}{l}\text { Age } \\
\text { (mean) }\end{array}$ & Male (\%) & Drug $(\mu \mathrm{g}$ & Device & $\begin{array}{l}\text { Current } \\
\text { smokers } \\
(\%)\end{array}$ & $\begin{array}{l}\text { Smoking } \\
\text { history, } \\
\text { pack-y }\end{array}$ & $\begin{array}{l}\text { Baseline } \\
\mathrm{FEV}_{1} \mathrm{~L}(\%)\end{array}$ & $\begin{array}{l}\text { Primary } \\
\text { outcome }\end{array}$ \\
\hline $\begin{array}{l}\text { Donohue } \\
\text { et al. } \\
2010 \text { (23) }\end{array}$ & $\begin{array}{l}\text { Moderate-to- } \\
\text { severe }\end{array}$ & 26 & 415 & 64 & $269(64.8)$ & $\mathrm{T}[18]$ & $\mathrm{DPI}$ & NA & 50.8 & 1.45 (53.9) & $\begin{array}{l}\text { Trough FEV } \\
\text { at week } 12\end{array}$ \\
\hline \multirow{3}{*}{$\begin{array}{l}\text { Bateman } \\
\text { et al. } \\
2013 \text { (20) }\end{array}$} & \multirow{3}{*}{$\begin{array}{l}\text { Moderate-to- } \\
\text { severe }\end{array}$} & \multirow[t]{3}{*}{26} & 476 & 63.9 & $354(74.4)$ & I [150] & DPI & $184(38.7)$ & NA & $1.5(54.9)$ & \multirow{3}{*}{$\begin{array}{l}\text { Trough FEV } \\
\text { at week } 26\end{array}$} \\
\hline & & & 473 & 64.3 & 365 (77.2) & $\mathrm{G}[50]$ & $\mathrm{DPI}$ & $189(40.0)$ & NA & $1.5(55.1)$ & \\
\hline & & & 480 & 63.5 & $360(75.0)$ & $\mathrm{T}[18]$ & $\mathrm{DPI}$ & $189(37.4)$ & NA & $1.5(55.1)$ & \\
\hline \multirow{2}{*}{$\begin{array}{l}\text { Celli et al. } \\
2014 \text { (25) }\end{array}$} & \multirow{2}{*}{$\begin{array}{l}\text { Moderate-to- } \\
\text { severe }\end{array}$} & \multirow[t]{2}{*}{24} & 404 & 62.8 & 265 (65.6) & V [25] & DPI & 210 (52.0) & 42.8 & NA (47.7) & \multirow{2}{*}{$\begin{array}{l}\text { Trough FEV } \\
\text { at week } 24\end{array}$} \\
\hline & & & 407 & 63.1 & 270 (66.3) & U [125] & DPI & 216 (53.0) & 39.6 & NA (47.6) & \\
\hline \multirow{2}{*}{$\begin{array}{l}\text { Decramer } \\
\text { et al. } \\
2014 \text { (19) }\end{array}$} & \multirow{2}{*}{$\begin{array}{l}\text { Moderate-to- } \\
\text { severe }\end{array}$} & \multirow[t]{2}{*}{24} & 209 & 63.2 & $143(68.4)$ & $\mathrm{V}[25]$ & $\mathrm{DPI}$ & $106(51.0)$ & 41.6 & NA (47.7) & \multirow{2}{*}{$\begin{array}{l}\text { Trough FEV } \\
\text { at week } 24\end{array}$} \\
\hline & & & 208 & 62.6 & $140(67.3)$ & $\mathrm{T}[18]$ & $\mathrm{DPI}$ & $99(48.0)$ & 41.9 & NA (47.8) & \\
\hline \multirow{2}{*}{$\begin{array}{l}\text { Buhl et al. } \\
2015 \text { (26) }\end{array}$} & \multirow{2}{*}{$\begin{array}{l}\text { Moderate-to- } \\
\text { severe }\end{array}$} & \multirow[t]{2}{*}{52} & 1,038 & 64.2 & 764 (73.6) & $\mathrm{O}[5]$ & SMI & $378(36.4)$ & NA & $1.377(50.3)$ & \multirow{2}{*}{$\begin{array}{l}\text { Trough FEV } \\
\text { and SGRQ } \\
\text { total score at } \\
\text { week } 24\end{array}$} \\
\hline & & & 1,033 & 63.9 & 755 (73.1) & $\mathrm{T}[5]$ & SMI & $370(35.8)$ & NA & $1.37(49.7)$ & \\
\hline
\end{tabular}

DPI, dry powder inhaler; SMI, soft mist inhaler; G, glycopyrronium; I, indacaterol; O, olodaterol; T, tiotropium; V, vilanterol; U, umeclidinium; SGRQ, St George's Respiratory Questionnaire; FEV ${ }_{1}$, forced expiratory volume in $1 \mathrm{~s}$.

Results obtained from 10,591 patients with COPD [LABA $(\mathrm{n}=5,058)$; LAMA $(\mathrm{n}=5,533)]$ were selected from 7 published papers. Three studies reported on indacaterol $v s$. tiotropium $(16,23,24)$ and one study on indacaterol $v s$. tiotropium and indacaterol $v s$. glycopyrronium (20). There were one study with vilanterol $v s$. umeclidinium (25), one study with vilanterol $v s$. tiotropium (19), and one study with olodaterol vs. tiotropium (26).

All studies published by March 2017 were included, and relevant patient baseline characteristics are summarized in Table 1. All RCTs were randomized and double-blind, and we included comparisons with open-label tiotropium in the RCTs. The duration of follow-up ranged from 12 to 56 weeks.

\section{Primary outcome}

As shown in Figure 2A, the analysis of 7 studies comparing ultra-LABA with ultra-LAMA showed that ultra-LAMA resulted in less frequent COPD exacerbations than ultra-
LABA $(\mathrm{OR}=0.857 ; 95 \%$ CI, 0.783-0.938; $\mathrm{P}=0.0008)$. When the one paper with only severe COPD was excluded in the meta-analysis (16), COPD exacerbation also occurred less frequently with ultra-LAMA than ultra-LABA $(\mathrm{OR}=0.885$; 95\% CI, 0.784-0.998; $\mathrm{P}=0.0471$ ) (Figure 2B).

\section{Secondary outcomes}

\section{Change of trough $\mathrm{FEV}_{1}$ from baseline}

Regarding change of trough $\mathrm{FEV}_{1}$ from baseline to the first follow-up after week 12 ( $\geq$ week 12), the data from 3 out of 7 studies were available for the means and standard errors of changes. The one study reported results at week 12 (23), and the remaining two studies reported results at week $24(19,25)$. The analysis of three studies of ultraLABA and ultra-LAMA showed no significant differences in the change of trough $\mathrm{FEV}_{1}$ at either week 12 or 24 from baseline (MD =-11.510 mL; 95\% CI, -33.330-10.309; $\mathrm{P}=0.3012$ ) (Figure 3). 

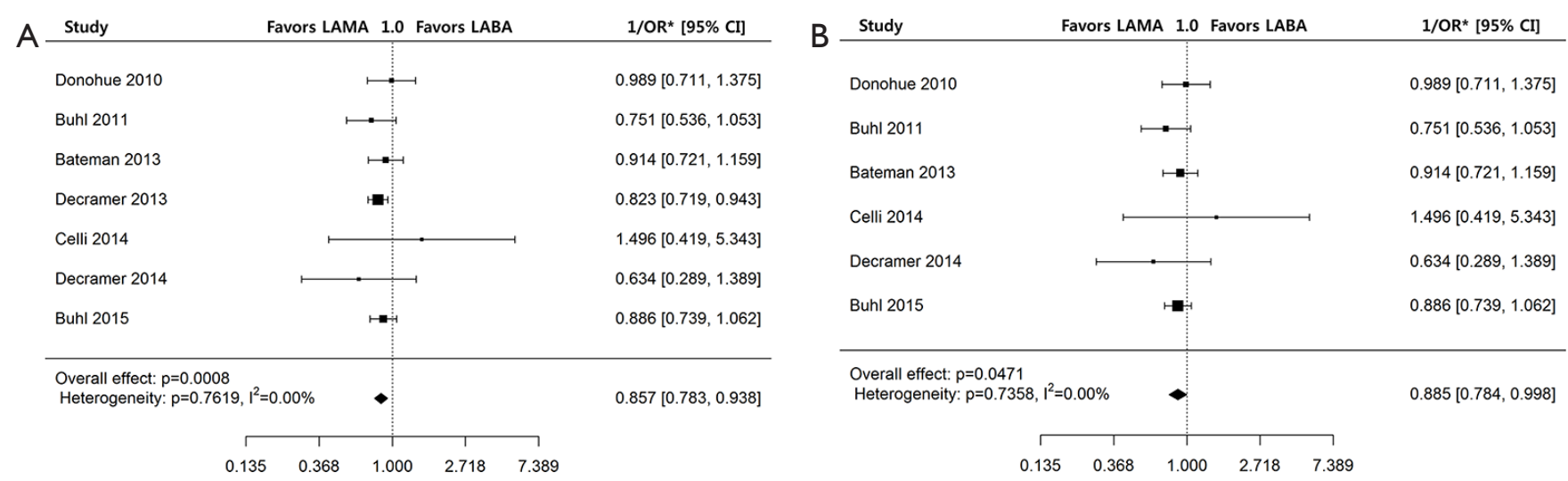

Figure 2 Forest plot of meta-analysis for the impact of ultra-LAMA vs. ultra-LABA on COPD exacerbations in patients with moderate to (A) severe COPD/fixed effect model (B) severe COPD except for one study including severe COPD patients (16)/fixed effect model. *reference=ultra-LAMA. COPD, chronic obstructive pulmonary disease; ultra-LAMA, ultra-long acting muscarinic antagonist; ultra-LABA, ultra-long acting $\beta_{2}$-agonist.

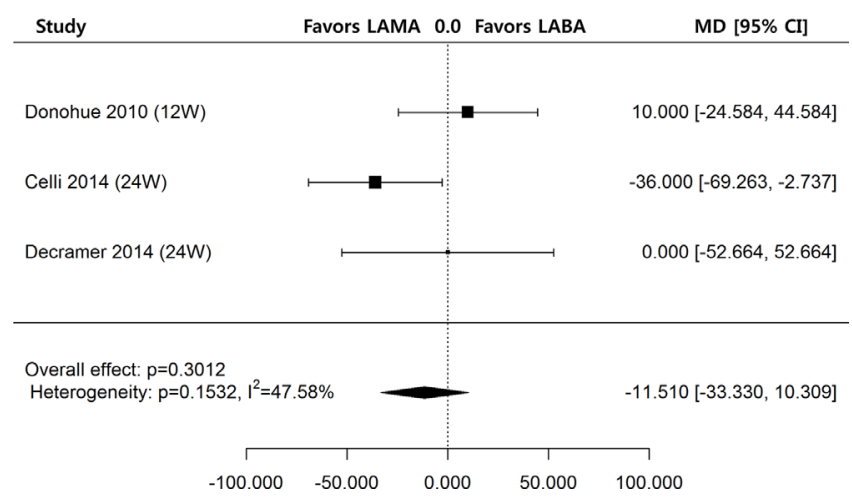

Figure 3 Forest plot of meta-analysis for the impact of ultraLAMA versus ultra-LABA on changes in trough $\mathrm{FEV}_{1}(\mathrm{~mL})$ at weeks 12 and 24 from baseline/fixed effects model. FEV $\mathrm{F}_{1}$, forced expiratory volume in one second; Ultra-LAMA, ultra-long acting muscarinic antagonist; ultra-LABA, ultra-long acting $\beta_{2}$-agonist.

\section{SGRQ score and TDI changes}

At the first follow-up, SGRQ total score was reported in six studies; the exception was one study in which only the change in SGRQ score was available (Figure 4A) (19). The SGRQ total scores at week 12 were reported in 3 studies $(16,23,24)$, at week 24 in 2 studies $(25,26)$, and at week 26 in the remaining studies (20). In these six studies, the MD was -0.621 , which was not significant (95\% CI, -1.603 to 0.362 ; $\mathrm{P}=0.2159)$.

At the first follow-up, TDI was reported in all 7 studies. The TDI at week 12 was reported in 3 studies $(16,23,24)$, at week 24 in 3 studies $(19,25,26)$, and at week 26 (20) in the remaining one study (Figure $4 B$ ). As shown in Figure $4 B$, there was no significant difference in TDI at the first follow-up between the ultra-LABA and ultra-LAMA groups ( $\mathrm{MD}=0.054 ; 95 \% \mathrm{CI},-0.197$ to $0.305 ; \mathrm{P}=0.6746)$.

\section{Heterogeneity and Bias in the included studies}

High levels of heterogeneity were detected on SGRQ total score change $\left(\mathrm{I}^{2}=99.82 \%, \mathrm{P}<0.0001\right)$ and TDI change $\left(\mathrm{I}^{2}=99.82 \%, \mathrm{P}<0.0001\right)$. There was moderate level of heterogeneity on change of trough $\mathrm{FEV}_{1}$ from baseline $\left(\mathrm{I}^{2}=47.58 \%, \mathrm{P}=0.1532\right)$ and mild level of heterogeneity on COPD exacerbation $\left(\mathrm{I}^{2}=0.00 \%, \mathrm{P}=0.7619\right)$. The assessments performed by the authors of each risk of bias item for each included RCT are summarized in Table 2. All papers were funded by pharmaceutical companies. Two studies were at high risk for blinding of participants and personnel because they used open-labeled tiotropium $(20,23)$. For publication bias, significant asymmetry in the funnel-plot was not detected for the primary and secondary outcomes $(\mathrm{P}=0.6630$ for $\mathrm{COPD}$ exacerbation, $\mathrm{P}=0.7898$ for change of trough $\mathrm{FEV}_{1}$ from baseline, $\mathrm{P}=0.7078$ for SGRQ total score change, and $\mathrm{P}=0.7495$ for TDI change) (Figure 5). Therefore, we assumed there was no evidence of publication bias.

\section{Discussion}

In this study, we performed a meta-analysis on the clinical efficacy and safety of ultra-LABA (indacaterol, olodaterol, or vilanterol) versus ultra-LAMA (glycopyrronium, 

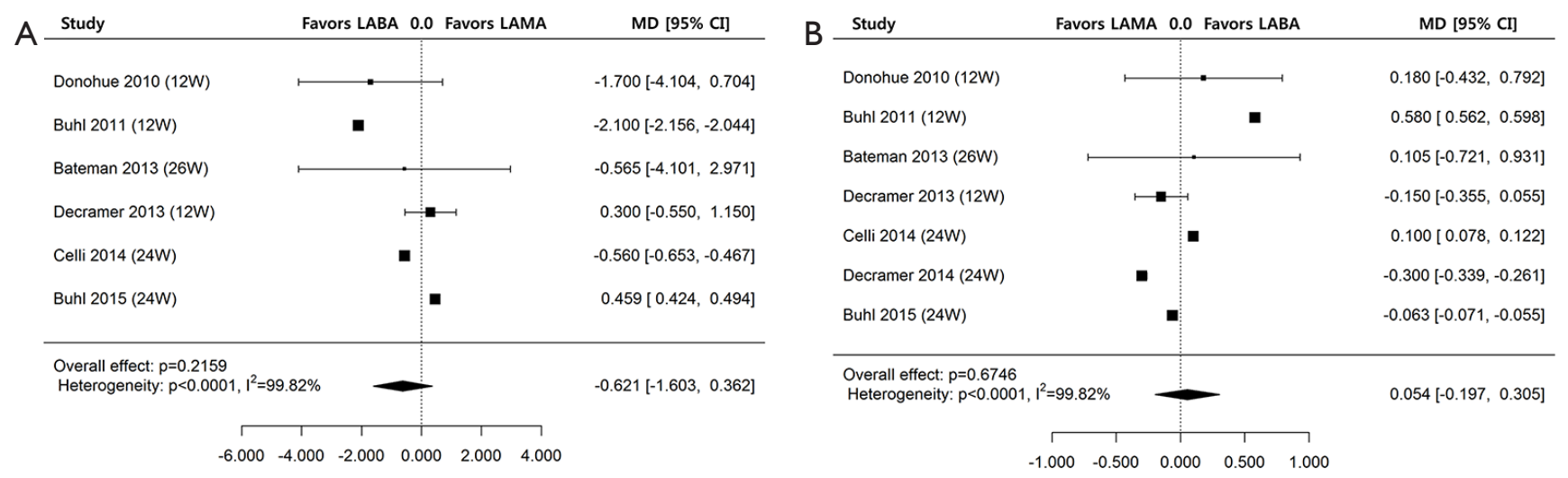

Figure 4 Forest plot of meta-analysis for the impact of ultra-LAMA versus ultra-LABA on (A) St. George's Respiratory Questionnaire score and (B) transition dyspnea index of the first time after follow-up/random effects model. Ultra-LAMA, ultra-long acting muscarinic antagonist; ultra-LABA, ultra-long acting $\beta_{2}$-agonist.

Table 2 Risk of Bias in the included studies

\begin{tabular}{|c|c|c|c|c|c|c|c|}
\hline Study & $\begin{array}{l}\text { Sequence } \\
\text { generation }\end{array}$ & $\begin{array}{l}\text { allocation } \\
\text { concealment }\end{array}$ & $\begin{array}{l}\text { Blinding of } \\
\text { participants } \\
\text { and personnel }\end{array}$ & $\begin{array}{l}\text { Blinding of } \\
\text { outcome } \\
\text { assessment }\end{array}$ & $\begin{array}{l}\text { Incomplete } \\
\text { outcome data }\end{array}$ & $\begin{array}{l}\text { Selective } \\
\text { reporting }\end{array}$ & Other bias \\
\hline Buhl et al. 2011 (24) & Unclear & Low risk & Low risk & Low risk & Low risk & Low risk & High risk \\
\hline Bateman et al. 2013 (20) & Unclear & Unclear & High risk & Low risk & Low risk & Low risk & High risk \\
\hline Celli et al. 2014 (25) & Unclear & Unclear & Unclear & Unclear & Low risk & Low risk & High risk \\
\hline Decramer et al. 2014 (19) & Low risk & Low risk & Low risk & Low risk & Low risk & Low risk & High risk \\
\hline Buhl et al. 2015 (26) & Unclear & Unclear & Unclear & Unclear & Low risk & Low risk & High risk \\
\hline
\end{tabular}

tiotropium, or umeclidinium) in stable patients with moderate-to-severe COPD. The main finding of this meta-analysis was that COPD exacerbation occurred less often with the ultra-LAMAs than ultra-LABAs among patients with moderate-to-severe COPD, while ultraLAMAs were as effective as ultra-LABAs in terms of trough $\mathrm{FEV}_{1}$ and quality of life including SGRQ and TDI at the first follow-up.

A previous meta-analysis based on four studies [Donohue et al. (23), Buhl et al. (24), Bateman et al. (20), and Decramer et al. (16)] comparing the clinical efficacy and safety of tiotropium, a ultra-LAMA, and indacaterol, a ultra-LABA, showed that COPD worsening was more frequent in the indacaterol group than in the tiotropium group (27). We affirmed these findings with various types of ultra-LABAs and ultra-LAMAs and a larger number of studies. Our findings also support the current recommendations of the GOLD guideline (1), which reports an advantage of ultraLAMAs over ultra-LABAs in exacerbation-prevention properties. The potential mechanisms might be explained by the anti-inflammatory effects of LAMA (28), which was shown in an animal model of COPD (e.g., reduction of neutrophils and proinflammatory cytokine levels and inhibition of mucus secretion as well as airway remodeling) (29-31). However, the results of our study need careful interpretation. First, we used COPD worsening in the adverse events for the analysis of COPD exacerbation except for Decramer et al. (19) as COPD worsening has comprehensive meaning including exacerbation. This is because only one head-to-head comparative study between tiotropium and indacaterol for COPD exacerbation has been published. Secondly, the number of studies including 

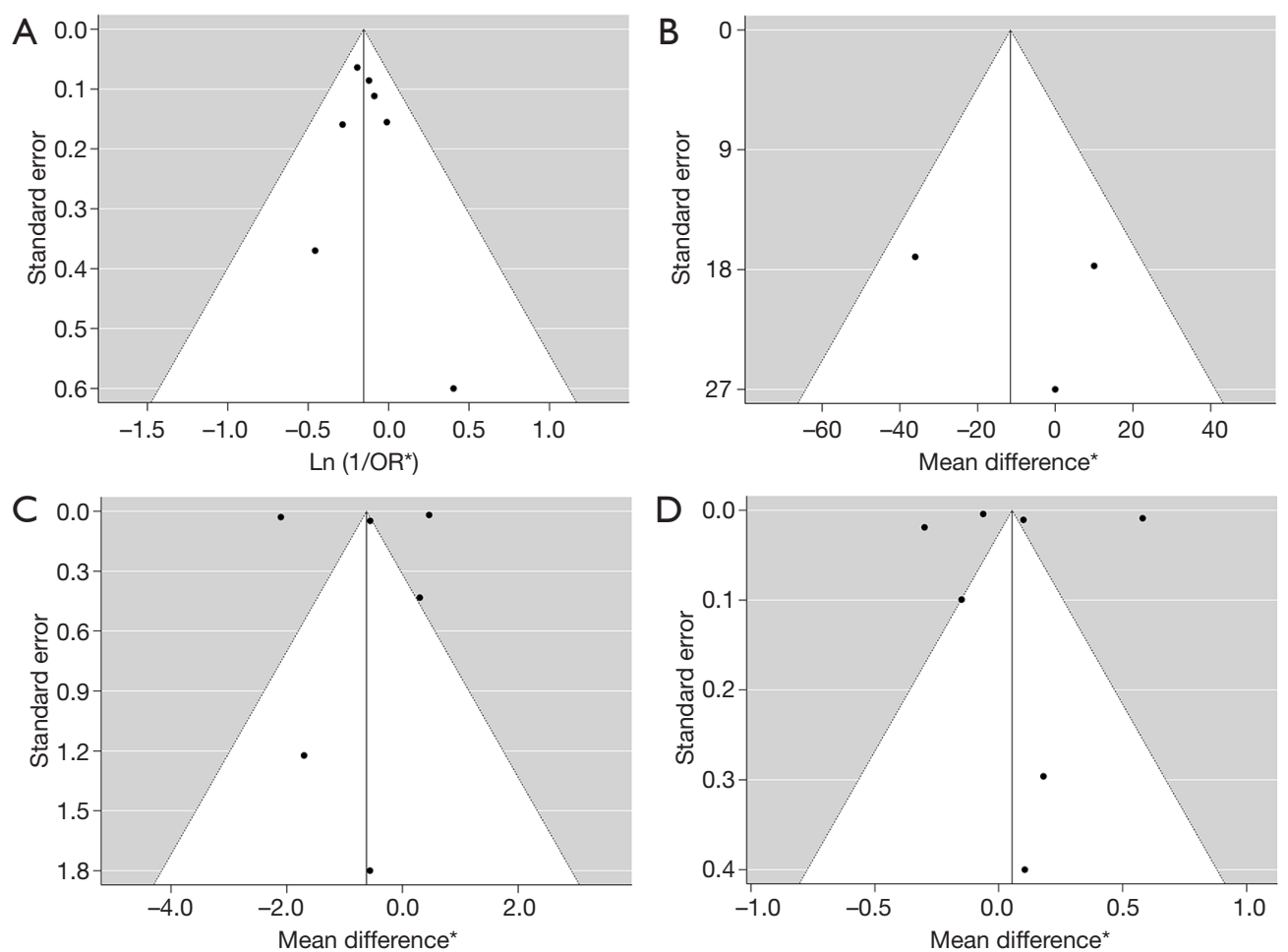

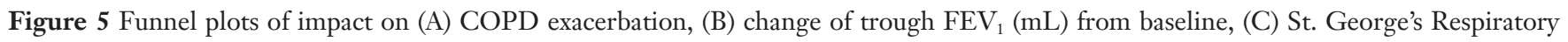
Questionnaire score, and (D) transition dyspnea index score. *reference= ultra-LAMA. COPD, chronic obstructive pulmonary disease; $\mathrm{FEV}_{1}$, forced expiratory volume in one second.

ultra-LAMAs or ultra-LABAs other than tiotropium or indacaterol was relatively small. In addition, since a considerable number of studies in our study included tiotropium, it might not be generalized to all ultra-LAMAs. When in vitro pharmacological profiles were observed using human bronchus, the potency, onset of action, and offset of action were different among LAMAs (32). In addition, as most studies on the anti-inflammatory effects of LAMAs were performed with tiotropium $(33,34)$, further studies are needed to elucidate whether other ultra-LAMAs exhibit similar features to tiotropium (31).

With respect to lung function, our study showed results with the change of trough $\mathrm{FEV}_{1}$ from baseline, which was consistent with the previous meta-analysis showing no significant differences of trough $\mathrm{FEV}_{1}$ at week 12 between the indacaterol and tiotropium groups (27). Ultra-LAMAs also showed a similar effect to ultra-LABAs with respect to quality of life measured by SGRQ total score and TDI in the analyses including data at 12 weeks $(16,23,24)$, 24 weeks $(19,25,26)$, or 26 weeks (20). However, in the subgroup analysis, compared to ultra-LAMAs, ultra-LABAs significantly improved SGRQ total score and TDI at 12 weeks (Figure $S 1 A, S 1 B$ ). The significant differences in SGRQ total score and TDI at 12 weeks between ultra-LAMAs and ultra-LABAs might suggest a faster improvement of quality of life in ultra-LABAs than ultraLAMAs despite significant heterogeneities in the analyses.

Our study has an advantage that our analyses were relatively free of publication bias in funnel plots, which enhances the reliability of the results of the meta-analyses. Although high levels of heterogeneity were detected in SGRQ total score change and TDI change, there was only mild heterogeneity in COPD exacerbation. Thus, the exacerbation prevention effect of ultra-LAMA over ultraLABA, the primary outcome in this study, can be considered to be based on high quality of meta-analyses, which is a major strength of this study.

In summary, this study suggests that COPD exacerbation occurred less often with ultra-LAMAs than ultra-LABAs with no significant differences in improvement of lung function or quality of life in moderate-to-severe COPD patients. 


\section{Acknowledgements}

None.

\section{Footnote}

Conflicts of Interest: CK Rhee has received consulting/ lecture fees from MSD, AstraZeneca, Novartis, GSK, Takeda, Mundipharma, Sandoz, Boehringer-Ingelheim, and Teva-Handok. HY Park has received lecture fees from AstraZeneca, Novartis, and Boehringer-Ingelheim. The other authors have no conflicts of interest to declare.

\section{References}

1. GOLD. Global Strategy for the Diagnosis, Management and Prevention of COPD, Global Initiative for Chronic Obstructive Lung Disease (GOLD) 2018. Available online: http://www.goldcopd.org/. Accessed April 4, 2018.

2. Lopez AD, Shibuya K, Rao C, et al. Chronic obstructive pulmonary disease: current burden and future projections. Eur Respir J 2006;27:397-412.

3. Donaldson GC, Seemungal TA, Bhowmik A, et al. Relationship between exacerbation frequency and lung function decline in chronic obstructive pulmonary disease. Thorax 2002;57:847-52.

4. Kanner RE, Anthonisen NR, Connett JE. Lower respiratory illnesses promote $\mathrm{FEV}(1)$ decline in current smokers but not ex-smokers with mild chronic obstructive pulmonary disease: results from the lung health study. Am J Respir Crit Care Med 2001;164:358-64.

5. Kessler R, Stahl E, Vogelmeier C, et al. Patient understanding, detection, and experience of COPD exacerbations: an observational, interview-based study. Chest 2006;130:133-42.

6. Spencer S, Calverley PM, Burge PS, et al. Impact of preventing exacerbations on deterioration of health status in COPD. Eur Respir J 2004;23:698-702.

7. Piquet J, Chavaillon JM, David P, et al. High-risk patients following hospitalisation for an acute exacerbation of COPD. Eur Respir J 2013;42:946-55.

8. Singanayagam A, Schembri S, Chalmers JD. Predictors of mortality in hospitalized adults with acute exacerbation of chronic obstructive pulmonary disease. Ann Am Thorac Soc 2013;10:81-9.

9. Gunen H, Hacievliyagil SS, Kosar F, et al. Factors affecting survival of hospitalised patients with COPD. Eur Respir J 2005;26:234-41.
10. Soler-Cataluña JJ, Martinez-Garcia MA, Roman Sanchez P, et al. Severe acute exacerbations and mortality in patients with chronic obstructive pulmonary disease. Thorax 2005;60:925-31.

11. Farne HA, Cates CJ. Long-acting beta2-agonist in addition to tiotropium versus either tiotropium or longacting beta2-agonist alone for chronic obstructive pulmonary disease. Cochrane Database Syst Rev 2015;(10):CD008989.

12. Kornmann O, Dahl R, Centanni S, et al. Oncedaily indacaterol versus twice-daily salmeterol for COPD: a placebo-controlled comparison. Eur Respir J 2011;37:273-9.

13. Korn S, Kerwin E, Atis S, et al. Indacaterol once-daily provides superior efficacy to salmeterol twice-daily in COPD: a 12-week study. Respir Med 2011;105:719-26.

14. Dahl R, Chung KF, Buhl R, et al. Efficacy of a new oncedaily long-acting inhaled beta2-agonist indacaterol versus twice-daily formoterol in COPD. Thorax 2010;65:473-9.

15. Vogelmeier C, Hederer B, Glaab T, et al. Tiotropium versus salmeterol for the prevention of exacerbations of COPD. N Engl J Med 2011;364:1093-103.

16. Decramer ML, Chapman KR, Dahl R, et al. Once-daily indacaterol versus tiotropium for patients with severe chronic obstructive pulmonary disease (INVIGORATE): A randomised, blinded, parallel-group study. Lancet Respir Med 2013;1:524-33.

17. Moher D, Liberati A, Tetzlaff J, et al. Preferred reporting items for systematic reviews and meta-analyses: the PRISMA statement. PLoS Med 2009;6:e1000097.

18. Domingo C. Ultra-LAMA, ultra-LABA, ultra-inhaled steroids? The future has landed. Arch Bronconeumol 2013;49:131-4.

19. Decramer M, Anzueto A, Kerwin E, et al. Efficacy and safety of umeclidinium plus vilanterol versus tiotropium, vilanterol, or umeclidinium monotherapies over 24 weeks in patients with chronic obstructive pulmonary disease: results from two multicentre, blinded, randomised controlled trials. Lancet Respir Med 2014;2:472-86.

20. Bateman ED, Ferguson GT, Barnes N, et al. Dual bronchodilation with QVA149 versus single bronchodilator therapy: The SHINE study. Eur Respir J 2013;42:1484-94.

21. Higgins JP, Altman DG, Gøtzsche PC, et al. The Cochrane Collaboration's tool for assessing risk of bias in randomised trials. BMJ 2011;343:d5928.

22. Egger M, Smith GD, Schneider M, et al. Bias in metaanalysis detected by a simple, graphical test. BMJ 1997;315:629-34. 
23. Donohue JF, Fogarty C, Lotvall J, et al. Once-daily bronchodilators for chronic obstructive pulmonary disease: indacaterol versus tiotropium. Am J Respir Crit Care Med 2010;182:155-62.

24. Buhl R, Dunn LJ, Disdier C, et al. Blinded 12-week comparison of once-daily indacaterol and tiotropium in COPD. Eur Respir J 2011;38:797-803.

25. Celli B, Crater G, Kilbride S, et al. Once-daily umeclidinium/vilanterol 125/25 mcg in COPD: a randomized, controlled study. Chest 2014;145:981-91.

26. Buhl R, Maltais F, Abrahams R, et al. Tiotropium and olodaterol fixed-dose combination versus monocomponents in COPD (GOLD 2-4). Eur Respir J 2015;45:969-79.

27. Kim JS, Park J, Lim SY, et al. Comparison of clinical efficacy and safety between indacaterol and tiotropium in COPD: Meta-analysis of randomized controlled trials. PLoS One 2015;10:e119948.

28. Kistemaker LE, Gosens R. Acetylcholine beyond bronchoconstriction: roles in inflammation and

Cite this article as: Cho EY, Kim SY, Kim MJ, Kim S, Park DA, Yoo KH, Park YB, Hwang YI, Rhee CK, Jung JY, Lee H, Park HY. Comparison of clinical efficacy between ultraLABAs and ultra-LAMAs in COPD: a systemic review with meta-analysis of randomized controlled trials. J Thorac Dis 2018;10(12):6522-6530. doi: 10.21037/jtd.2018.11.50 remodeling. Trends Pharmacol Sci 2015;36:164-71.

29. Wollin L, Pieper MP. Tiotropium bromide exerts antiinflammatory activity in a cigarette smoke mouse model of COPD. Pulm Pharmacol Ther 2010;23:345-54.

30. Pera T, Zuidhof A, Valadas J, et al. Tiotropium inhibits pulmonary inflammation and remodelling in a guinea pig model of COPD. Eur Respir J 2011;38:789-96.

31. Alagha K, Palot A, Sofalvi T, et al. Long-acting muscarinic receptor antagonists for the treatment of chronic airway diseases. Ther Adv Chronic Dis 2014;5:85-98.

32. Naline E, Grassin Delyle S, Salvator H, et al. Comparison of the in vitro pharmacological profiles of long-acting muscarinic antagonists in human bronchus. Pulm Pharmacol Ther 2018;49:46-53.

33. Matthiesen S, Bahulayan A, Kempkens S, et al. Muscarinic receptors mediate stimulation of human lung fibroblast proliferation. Am J Respir Cell Mol Biol 2006;35:621-7.

34. Bühling F, Lieder N, Kuhlmann UC, et al. Tiotropium suppresses acetylcholine-induced release of chemotactic mediators in vitro. Respir Med 2007;101:2386-94. 


\section{Supplementary}
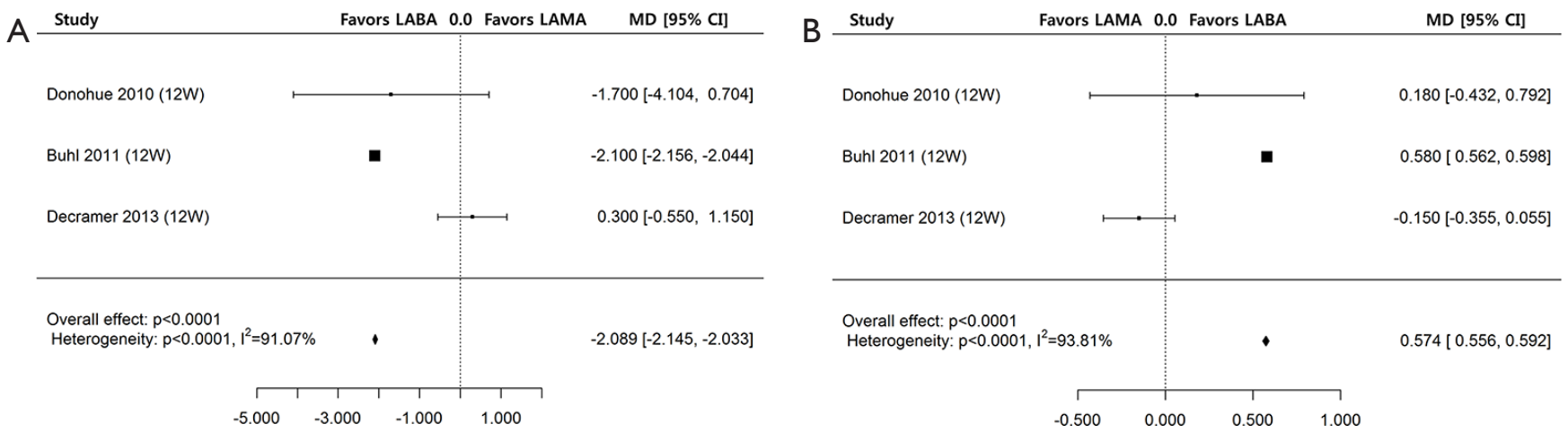

Figure S1 Subgroup analysis for the impact of ultra-LAMA versus ultra-LABA on (A) St. George's Respiratory Questionnaire score and (B) transition dyspnea index at week 12/fixed effects model. 